\title{
Novel Current-Mode All-Pass Filter with Minimum Component Count
}

\author{
Jitendra Mohan, Bhartendu Chaturvedi \\ Department of Electronics and Communication Engineering, Jaypee Institute of Information Technology \\ Noida, India \\ jitendramv2000@rediffmail.com, bhartendu.prof@gmail.com
}

Sudhanshu Maheshwari

Department of Electronics Engineering, Z. H. College of Eng ineering and Technology, Aligarh Muslim University, Aligarh, India

\begin{abstract}
In this paper, two novel first order currentmode all-pass filters are proposed using a resistor and a grounded capacitor along with a multi-output dual-X second-generation current conveyor (MO-DXCCII). There is no element matching restriction. Both the circuits exhibit low input and high output impedance, which is a desirable feature for current-mode circuits. The proposed circuits are simulated using SPICE simu lation program to confirm the theory.
\end{abstract}

Index Terms - Analog signal processing, DXCCII, current-mode, all-pass filter.

\section{INTRODUCTION}

Current-mode (CM) circuits have become popular due to their advantages such as wider dynamic range, inherent wider bandwidth, simple circuitry and low power consumption over the voltage-mode counterparts [1]. On the other hand, a CM circuit with features of low input and high output impedance is of special interest as there is no need for additional circuitry or active element for cascading or interfacing within a system and it also decreases the number of active elements in the system. First order all-pass filters (APF) are very useful building block for many analog signal processing applications such as for the realization of multiphase oscillators, high $\mathrm{Q}$ band pass filters, phase equalizers and also for introducing frequency dependent delay while keeping the amplitude of the input signal constant over a frequency range of interest. Recently, the design of first-order current-mode all-pass filter (CMAPF) has received attention for the use of minimal number of active and passive components (i.e. one active element and two passive components).

Numerous first-order CMAPF circuits were proposed using different types of current-mode active building blocks in the literature [2-15]. Some of these circuits are based on single active element [3-5, 7-10, 12, 14]. The reported single active element based circuits as described in $[3-5,7,10,12]$ employ more than two passive components, but show the feature of high output impedance suited for $\mathrm{CM}$ cascading. Moreover the circuits described in [6,11, 13-14] fall in category of tunable, resistorless realizations. The most recent of these described in [14] shows low input and high output impedance feature with single active element and one capacitor. The circuit described in [8] employs one current differencing buffered amplifier (CDBA), one capacitor and one resistor. However, its input impedance is not low and the capacitor used is not grounded. The circuit given in [2] employs two active elements. The circuits presented in [5, 9] are based on minimal component count, but require additional current conveyor to sense the output current. The recently published allpass filter in [15] employs two active elements and two passive components, but exhibits low input and high output impedances.

In this paper, two new CMAPFs employing a single multi-output dual-X second-generation current conveyor (MO-DXCCII) are presented. The proposed circuits employ only one resistor and one capacitor and require no element matching restriction. Each circuit possesses low input and high output impedance. The proposed circuits consist of one lesser active element in comparis on to paper [15]. To support the theory, PSPICE simulation results using TSMC $0.35 \mu \mathrm{m}$ CMOS parameters are included.

The paper is organized as follows: in section II, the description of DXCCII with its port relationship is presented. The proposed all-pass filters using MODXCCII are described in section III. In section IV, parasitic study and non-ideal analysis of the proposed circuits are given. In section $\mathrm{V}$, to verify the theoretical study, the first order current-mode all-pass filters are designed and simulated with SPICE simulation program. Finally, the conclusion is presented in section VI.

\section{MULTI-OUTPUT DUA L-X SECOND- GENERATION CURRENT CONVEYOR (DXCCII)}

Dual-X second generation current conveyor (DXCCII) [16] is a relatively recently introduced useful and versatile current-mode active element for analog signal processing applications [17-20]. It encompasses the advantages of second generation current conveyor (CCII) and inverting second generation current conveyor (ICCII). The 


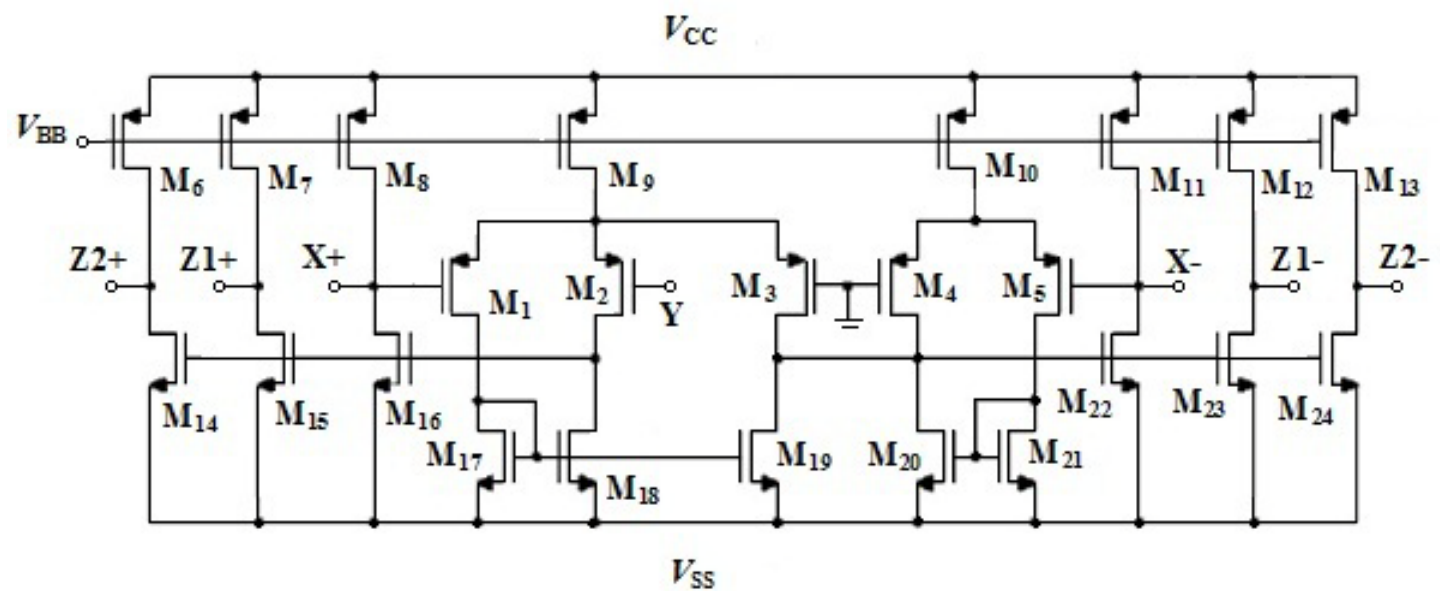

Figure 1. CMOS Implementation of MO-DXCCII [16]

practical realizations of this active element have been successfully explored using commercially available ICs [21]. The CMOS implementation of multi-output dual-X second-generation current conveyor (MO-DXCCII) is shown in Fig. 1. The port relationship of the MO-DXCCII can be characterized as:

$$
\left[\begin{array}{c}
I_{Y} \\
V_{X+} \\
V_{X-} \\
I_{Z 1+} \\
I_{Z 2+} \\
I_{Z 1-} \\
I_{Z 2-}
\end{array}\right]=\left[\begin{array}{ccc}
0 & 0 & 0 \\
1 & 0 & 0 \\
-1 & 0 & 0 \\
0 & 1 & 0 \\
0 & 1 & 0 \\
0 & 0 & 1 \\
0 & 0 & 1
\end{array}\right]\left[\begin{array}{l}
V_{Y} \\
I_{X+} \\
I_{X-}
\end{array}\right]
$$

\section{PROPOSED CIRCUITS}

The proposed CM-APFs are shown in Fig. 2. Both the circuits employ a single MO-DXCCII, and the minimal number of passive components (one resistor and one capacitor). Note that the capacitor used is in grounded form, which makes the circuits suitable for integrated circuit implementation. Routine analys is of the circuits of Fig. 2 yields the following current transfer function

CMAPF-II $: \frac{I_{\text {OUT }}}{I_{I N}}=-\left(\frac{s-\frac{1}{\left(C+C_{\mathrm{z} 1-}\right)\left(R+R x_{+}\right)}}{s+\frac{1}{\left(C+C_{\mathrm{z} 1-}\right)\left(R+R_{X+}\right)}}\right)$

The frequency dependent phase response $(\Phi)$ of the filters is given by

$\phi(\omega)=-2 \tan ^{-1}(\omega C R)$

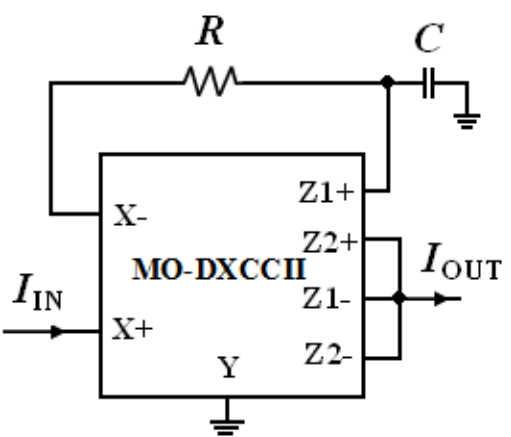

(a)

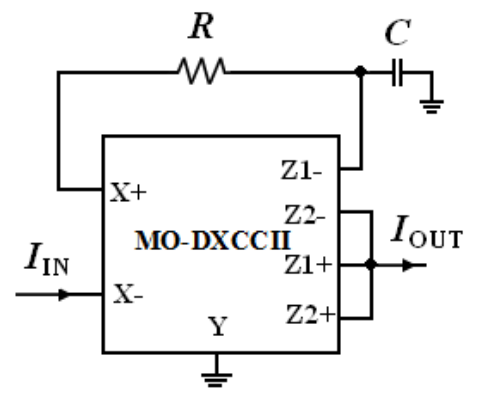

(b)

Figure 2. (a) CMAPF-I (b) CMAPF-II

It is to be noted from (2) that no passive element matching constraints are required for the proposed circuits. The proposed filters exhibit low input and high output impedance, which make them suitable for cascading without requiring additional current buffer circuit. The other salient features of the two proposed circuits are use of single active element and two passive components. The three features are not exhibited together in any of the available work [2-15]. As far as integrated aspect of the new proposed circuits are concerned, the resistor can be replaced by active-MOS resistor with the added advantage of tunability through external voltage [22] and the capacitor can be implemented in MOS technology [23]. 


\section{NON-IDEA L ANA LYSIS AND EFFECTS OF MO-DXCCII PARASITIC}

\section{A. Non-ideal Analysis}

Taking non-idealities of the MO-DXCCII into account, the port relationships of the voltages and currents modify to

$\left[\begin{array}{c}I_{Y} \\ V_{X+} \\ V_{X-} \\ I_{Z 1+} \\ I_{Z 2+} \\ I_{Z 1-} \\ I_{Z 2-}\end{array}\right]=\left[\begin{array}{ccc}0 & 0 & 0 \\ \beta_{1} & 0 & 0 \\ -\beta_{2} & 0 & 0 \\ 0 & \alpha_{1} & 0 \\ 0 & \alpha_{2} & 0 \\ 0 & 0 & \alpha_{3} \\ 0 & 0 & \alpha_{4}\end{array}\right]\left[\begin{array}{c}V_{Y} \\ I_{X+} \\ I_{X-}\end{array}\right]$

Here, $\alpha_{1}$ and $\alpha_{2}$ are the current transfer gains from $\mathrm{X}+$ terminals to $\mathrm{Z} 1+$ and $\mathrm{Z} 2+$ terminals, respectively $\alpha_{3}$ and $\alpha_{4}$ are the current transfer gains from $\mathrm{X}$ - terminals to Z1and $\mathrm{Z} 2$ - terminals, respectively and $\beta_{1}$ and $\beta_{2}$ are the voltage transfer gains from $\mathrm{Y}$ input terminal to $\mathrm{X}+$ and $\mathrm{X}$ - terminals, respectively. However, these transfer gains are close to unity up to a very high frequency range (i.e. in $\mathrm{GHz}$ ) [8].

The proposed circuits are reanalyzed assuming nonideal MO-DXCCII; the modified current transfer functions are found as

CMAPF-I: $\frac{I_{O U T}}{I_{I N}}=-\alpha_{2}\left[\frac{s+\frac{\alpha_{2}-\alpha_{3}-\alpha_{4}}{C R \alpha_{2}}}{s+\frac{1}{C R}}\right]$

CMAPF-II: $\frac{I_{\text {OUT }}}{I_{I N}}=-\alpha_{4}\left[\frac{s+\frac{\alpha_{4}-\alpha_{1}-\alpha_{2}}{C R \alpha_{4}}}{s+\frac{1}{C R}}\right]$

From (5) and (6), it is to be observed that the nonidealities do affect the filter gain, as it now depends on $\alpha_{2}$ and $\alpha_{4}$ for the CMAPF-1 and CMAPF-II, respectively but the pole frequency is unaltered by MO-DXCCII nonidealities. The pole-frequency $\left(\omega_{0}\right)$ and gain $(H)$ sensitivity for the all-pass filter circuits to the non-idealities as well as external components is analyzed and is tabulated in Table I.

From Table I, it is to be observed as the sensitivities of active and passive components with respect to pole frequency $\left(\omega_{0}\right)$ and gain $(H)$ are less than or equal to unity in magnitude meaning good sensitivity performance.
TABLE I. SEN SITIVITY FIGURES WITH RESPECT TO POLE FREQUENCY $\left(\omega_{0}\right)$ AND GAIN $(H)$ FORTHE PROPOSED CIRCUITS OF FIG. 2

\begin{tabular}{|c|c|c|c|c|c|}
\hline Circuit & $S_{\alpha_{1}, \alpha_{2}, \alpha_{3}, \alpha_{4}, \beta_{1}, \beta_{2}}^{\omega_{2}}$ & $S_{R, C}^{\omega_{o}}$ & $S_{\alpha_{2}}^{H}$ & $S_{\alpha_{4}}^{H}$ & $S_{\alpha_{1}, \alpha_{3}, \beta_{1}, \beta_{2}, R, C}$ \\
\hline CMAPF-I & 0 & -1 & 1 & 0 & 0 \\
\hline CMAPF-II & 0 & -1 & 0 & 1 & 0 \\
\hline
\end{tabular}

\section{B. Effects of MO-DXCCII Parasitic}

Effects of parasitics involved with the used current conveyor are now considered. The various parasitic involved with a typical MO-DXCCII are a small parasitic resistances $R_{\mathrm{X}^{+}}$and $R_{\mathrm{X}-}$ at $\mathrm{X}+$ and $\mathrm{X}$ - terminals respectively, parasitic at $\mathrm{Y}$ terminal is $\left(R_{\mathrm{Y}} / / C_{\mathrm{Y}}\right)$ and parasitic at $\mathrm{Z} 1+, \mathrm{Z} 2+, \mathrm{Z} 1$ - and $\mathrm{Z} 2$ - terminals are $\left(R_{\mathrm{Z} 1+} / / C_{\mathrm{Z} 1+}\right),\left(R_{\mathrm{Z} 2+} / / C_{\mathrm{Z} 2}\right),\left(R_{\mathrm{Z} 1-} / / C_{\mathrm{Z1}-}\right)$ and $\left(R_{\mathrm{Z} 2-} / / C_{\mathrm{Z} 2-}\right)$, respectively [24]. The parasitic model of MO-DXCCII is also shown in Fig. 3. Here, it is assumed that the circuits are restricted to work at frequencies much lower than the corner frequencies of $\beta_{\mathrm{i}}(\mathrm{i}=1,2)$ and $\alpha_{\mathrm{i}}(\mathrm{i}=1,2,3,4)$. But practically it is assumed that the external resistors are much smaller than the parasitic resistors at the $\mathrm{Y}$ and $\mathrm{Z}$ terminals of MO-DXCCII, i.e. $R<<R_{\mathrm{Y}}$ or $R_{\mathrm{Z} 1+}$ or $R_{\mathrm{Z} 2+}$ or $R_{\mathrm{Z1} \text { - }}$ or $R_{\mathrm{Z} 2 \text { - }}$ and the external resistors are much greater than the parasitic resistors at the $\mathrm{X}+$ and $\mathrm{X}$ - terminals of MO-DXCCII, i.e. $R_{\mathrm{X}^{+}}$or $R_{\mathrm{X}^{-}}<<R$. A re-analysis of the two circuits given in Fig. 2 yields the following transfer function

CMAPF-I $: \frac{I_{\text {OUT }}}{I_{I N}}=-\left(\frac{s-\frac{1}{\left(C+C_{z_{1}}\right)\left(R+R_{X-}\right)}}{s+\frac{1}{\left(C+C_{z_{1}}\right)\left(R+R_{X-}\right)}}\right)$

CMAPF-II $: \frac{I_{\text {OUT }}}{I_{I N}}=-\left(\frac{s-\frac{1}{\left(C+C_{z_{1}-}\right)\left(R+R_{X+}\right)}}{s+\frac{1}{\left(C+C_{z_{1}-}\right)\left(R+R_{X+}\right)}}\right)$

From (7) and (8), the parasitic resistances / capacitances get absorbed with the external values. Because the $\mathrm{X}$ terminal is connected directly to a resistor so the parasitic resistance at the X terminal of the MO-DXCCII $\left(R_{\mathrm{X}}\right)$ can be absorbed as a part of resistance $(R)$, where as the parasitic capacitances $\left(C_{\mathrm{Z1} 1}\right.$ or $\left.C_{\mathrm{Z1}+}\right)$ is in shunt with capacitor $(C)$. This causes slight deviation in circuit's parameters, which can be minimized by pre-distorting the designed values to be used in the circuits. It is also seen that the pole-frequency would be in error because of these parasitic. The error is expected to be small for an integrated MO-DXCCII; the actual value to be given in the 'simulation results'. 


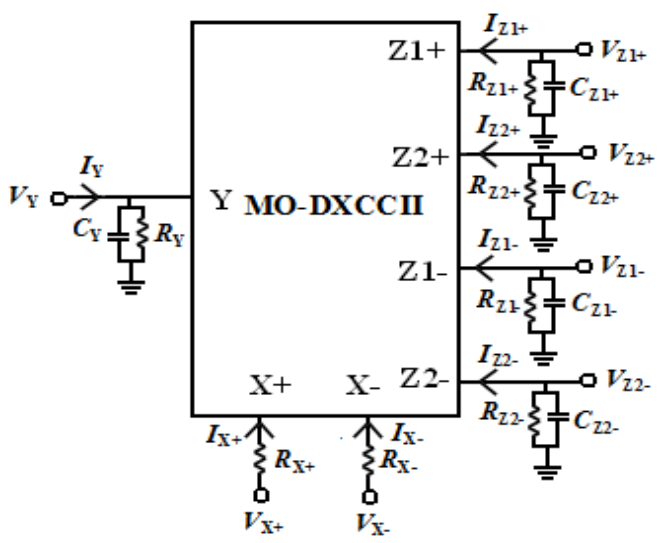

Figure 3. Parasitic Model of MO-DXCCII

\section{SIMULATION RESULTS}

The proposed circuits are verified using the PSPICE simulation program. The MO-DXCCII is realized by the CMOS implementation [16] of Fig. 1 using $0.35 \mu \mathrm{m}$ TSMC process parameters (Table II). The aspect ratios of NMOS and PMOS transistors are chosen as in Table III and the supply voltages used were $\pm 1.8 \mathrm{~V}$ and $\mathrm{V}_{\mathrm{BB}}=-$ $1.25 \mathrm{~V}$. The CMAPF-I is designed with $C=100 \mathrm{pF}$ and $R$ $=1 \mathrm{~K} \Omega$ for a theoretical pole frequency of $1.59 \mathrm{MHz}$ The phase and gain responses for the CMAPF-I are shown plotted in Fig. 4, which shows a constant unity gain and frequency dependent phase. A phase shift of $-90^{\circ}$ is obtained at the pole frequency and the pole frequency is found to be as $1.51 \mathrm{MHz}$, which is in consistency with the designed value. Next figure (Fig. 5) shows the time domain input and output waveforms, along with their Fourier spectrum when a sinusoidal input signal of frequency $1.59 \mathrm{MHz}$ is applied at the input terminal of the circuit. The output current is $-90^{\circ}$ phase shifted with respect to the input, which verifies circuit operation as a phase shifter. In addition, the Lissajous pattern for the circuit as $-90^{\circ}$ phase shifter is shown plotted in Fig. 6. The variation of the total harmonic distortion (THD) at the output by varying the amplitude of the sinusoidal input current at $1.59 \mathrm{MHz}$ is shown in Fig. 7. It can be seen that the THD value of the filter increases for the input current in excess to $200 \mu \mathrm{A}$ (peak to peak). The simulations confirm the proposed circuits and results agree with the theory.

\section{INTEGRATION ASPECTS}

The integration prospects of the new proposed circuits are considered here. The proposed current-mode first order all-pass filters employ single MO-DXCCII, which can be implemented in CMOS technology [16]. Both the circuits use a single grounded capacitor in its realization, which is suitable for integration. There are techniques to implement the capacitor in MOS technology [23, 25]. The resistor used in the circuits can be replaced by active MOS resistor, available in literature [22], with an added feature of tunability by control voltage. Thus the proposed circuits are suitable for IC implementation.
TABLE II. $0.35 \mu \mathrm{m}$ TSMC CMOS PROCESS PARAMETERS

\begin{tabular}{|c|}
\hline NMOS: \\
\hline NSUB=1E17 \\
\hline GAMMA $=0.5827871 \quad \mathrm{PHI}=0.7 \quad$ VTO $=0.5445549$ DELTA $=0$ \\
\hline $\mathrm{UO}=436.256147 \mathrm{ETA}=0$ THETA $=0.1749684 \mathrm{KP}=2.055786 \mathrm{E}-$ \\
\hline 4 VMAX $=8.309444 \mathrm{E} 4$ KAPPA $=0.2574081 \mathrm{RSH}=0.0559398$ \\
\hline $\mathrm{LD}=3.162278 \mathrm{E}-11$ \\
\hline $\mathrm{WD}=7.04672 \mathrm{E}-8 \quad \mathrm{CGDO}=2.82 \mathrm{E}-10$ \\
\hline $\mathrm{CGBO}=1 \mathrm{E}-10 \quad \mathrm{CJ}=1 \mathrm{E}-3 \quad \mathrm{~PB}=0.9758533$ \\
\hline CJSW $=3.777852 \mathrm{E}-10 \mathrm{MJSW}=0.3508721$ \\
\hline PMOS: \\
\hline NSUB=1E17 \\
\hline GAMMA $=0.4083894$ PHI $=0.7$ VTO $=0.7140674$ DELTA $=0$ \\
\hline $\mathrm{UO}=212.2319801 \quad$ ETA $=9.999762 \mathrm{E}-4 \quad$ THETA $=0.2020774$ \\
\hline VMAX $=1.181551 \mathrm{E} 5$ \\
\hline $\mathrm{RSH}=30.0712458$ \\
\hline $\mathrm{LD}=5.000001 \mathrm{E}-13$ \\
\hline $\mathrm{CGSO}=3.09 \mathrm{E}-10$ \\
\hline $\mathrm{PB}=0.8152753 \mathrm{MJ}=0.5 \mathrm{CJSW}=4.813504 \mathrm{E}-10 \mathrm{~N}$ \\
\hline
\end{tabular}

TABLE III. TRANSISTOR ASPECT RATIOSFOR THE CIRCUIT SHOWN IN FIG. 1.

\begin{tabular}{|l|c|c|}
\hline \multicolumn{1}{|c|}{ Transistors } & $\mathrm{W}(\mu \mathrm{m})$ & $\mathrm{L}(\mu \mathrm{m})$ \\
\hline $\mathrm{M}_{1}-\mathrm{M}_{2}$ & 1.4 & 0.7 \\
\hline $\mathrm{M}_{3}-\mathrm{M}_{5}$ & 2.8 & 0.7 \\
\hline $\mathrm{M}_{17}-\mathrm{M}_{18}$ & 2.4 & 0.7 \\
\hline $\mathrm{M}_{19}-\mathrm{M}_{21}$ & 4.8 & 0.7 \\
\hline $\mathrm{M}_{6}-\mathrm{M}_{16}, \mathrm{M}_{22}-\mathrm{M}_{24}$ & 9.6 & 0.7 \\
\hline
\end{tabular}

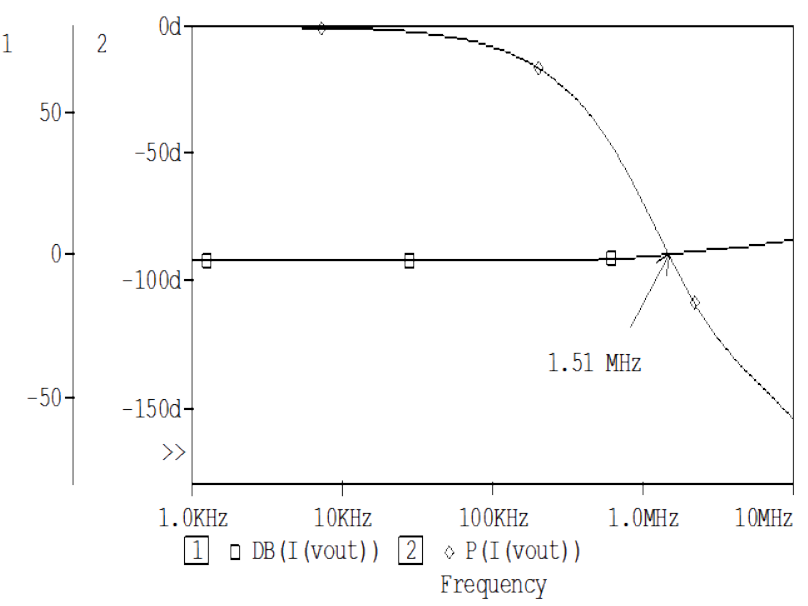

Figure 4. Simulated gain and phase response of CMAPF-I

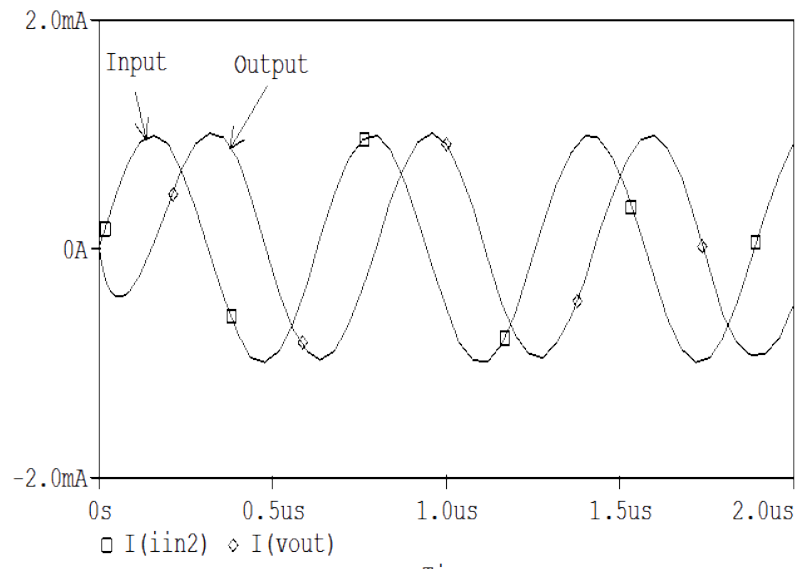

(a) Time 


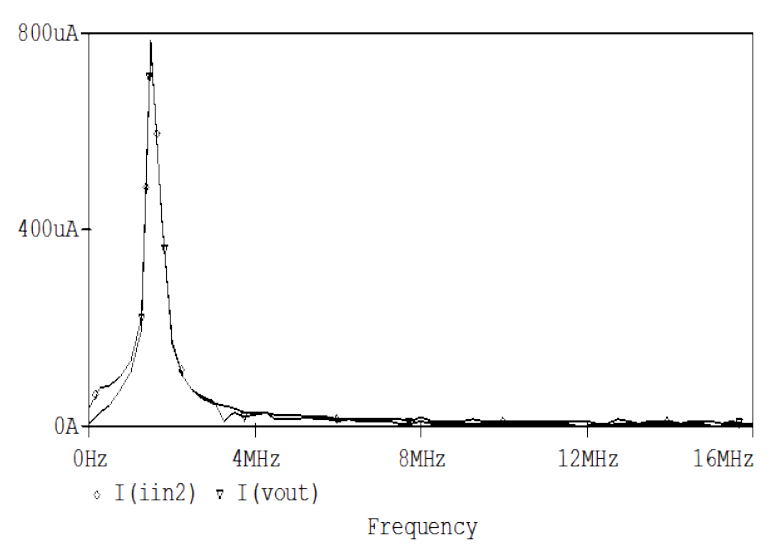

(b)

Figure 5. (a) Input/output responses (b) Fourier spectrum at $1.59 \mathrm{MHz}$

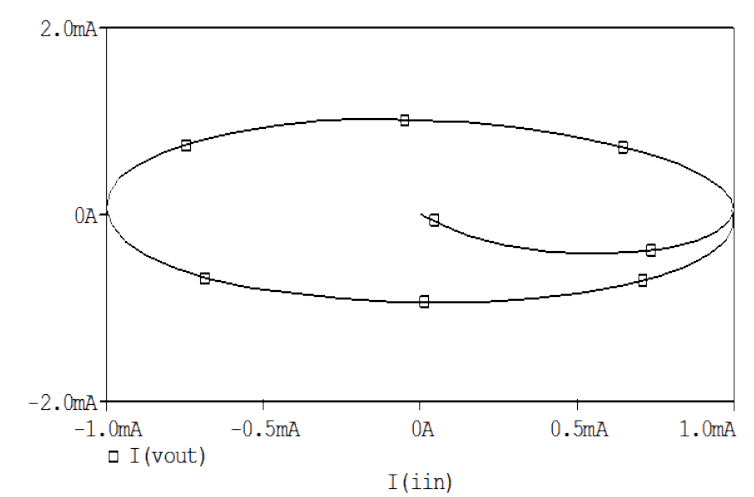

Figure 6. Lissajous pattern showing $-90^{\circ}$ phase shift at pole frequency

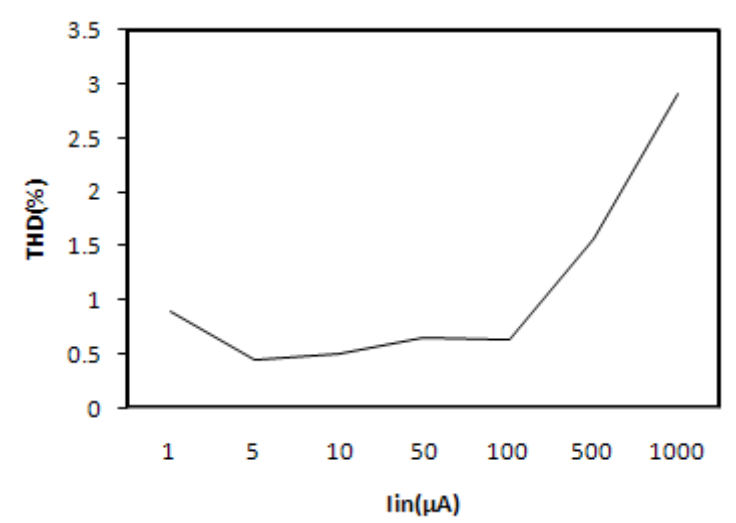

Figure 7. THD variation with the sinusoidal input signal at $1.59 \mathrm{MHz}$

\section{CONCLUSION}

This paper presents two novel first-order current-mode all-pass filters, employing minimal number of active and passive components i.e. single MO-DXCCII, one resistor and one capacitor. The proposed circuits show low input and high output impedance feature, which is desirable for the CM circuits. Beside this, the circuits employ grounded capacitor which is good for IC implementation in CMOS technology. No passive component matching constraints are required for the proposed filters. The simulation results confirm the workability of the proposed filters.

\section{ACKNOW LEDGMENT}

The corresponding authors are grateful to the anonymous referees for their useful comments, which helped to further improve the paper.

\section{REFERENCES}

[1] C. Toumazou, F. Lidjey and D. Haigh, “Analog IC design: the current-mode approach”, Peter Peregrinus, UK, 1990.

[2] A. Fabre and J. P. Longuemard, "High performance current processing all-pass filters", International Journal of Electronics, vol. 66, pp. 619-632, 1989.

[3] M. Higashimura and Y. Fukui, "Realization of current mode all-pass networks using a current conveyor", IEEE Transactions on Circuits and Systems, vol. 37, pp. 660-661, 1990.

[4] M. Higashimura, "Current-mode all-pass filter using FTFN with grounded capacitor", Electronics Letter, vol. 27, pp. 1182-1183, 1991.

[5] A. M. Soliman, "Theorems relating to port interchange in current-mode CCII circuits", International Journal of Electronics, vol. 82, pp. 582-604, 1997.

[6] T. Tsukutani, M. Higashimura, M. Ishida, S. Tsuiki, and Y. Fu kui, "A general class of current-mode highorder OTA-C filters”, International Journal of Electronics, vol. 81, pp. 663-669, 1996.

[7] A. M. Soliman, "New current mode filters using current conveyors", International Journal of Electronics and Communications (AEÜ), vol. 51, pp. 275-278, 1997.

[8] A. Toker, S. Ozoguz, O. Cicekoglu and C. Acar, "Current-mode all-pass filters using current differencing buffered amplifier and a new high-Q band-pass filter configuration”, IEEE Transactions on Circuits and Systems II: Analog and Digital Signal Processing, vol. 47, pp. 949-954, 2000.

[9] S. Maheshwari and I. A. Khan, "Novel first order allpass sections using a single CCIII”, International Journal of Electronics, vol. 88, pp. 773-778, 2001.

[10] S. Kilinc and U. Cam, "Current-mode first-order allpass filter employing single current operational amplifier”, Analog Integrated Circuits and Signal Processing, vol. 41, pp. 47- 53, 2004.

[11] S. Maheshwari, "New voltage and current-mode APS using current controlled conveyor", International Journal of Electronics, vol. 91, pp. 735-743, 2004.

[12] S. Minaei and M. A. Ibrahim, “General configuration for realizing current-mode first order all-pass filter using DVCC”, International Journal of Electronics, vol. 92, pp. 347-356, 2005.

[13] S. Maheshwari, “A new current-mode currentcontrolled all-pass section”, Journal of Circuits, Systems and Computers, vol. 16, pp. 181-189, 2007.

[14] D. Biolek and V. Biolkova, “All-pass filter employing one grounded capacitor and one active 
element”, Electronics Letters, vol. 45, pp. 807-808, 2009.

[15] S. Minaei and E. Yuce, “All grounded passive elements current-mode All-pass filter", Journal of Circuits, Systems and Computers, vol. 18, pp. 31-43, 2009.

[16] A. Zeki and A. Toker, "The dual-X current conveyor (DXCCII): A new active device for tunable continuous-time filters”, International Journal of Electronics, vol. 89, pp. 913-923, 2002.

[17] A. Zeki and A. Toker, "DXCCII-based tunable gyrator", International Journal of Electronics and Communications (AEÜ), vol. 34, pp. 59-62, 2005.

[18] S. Minaei, “Electronically tunable current-mode universal biquad filter using dual-X current conveyors", Journal of Circuits, Systems, and Co mputers, vol. 18, pp. 665-680, 2009.

[19] S. Minaei and E. Yuce, "A new full-wave rectifier circuit employing single dual-X current conveyor", International Journal of Electronics, vol. 95, pp. 777-784, 2008.

[20] S. Maheshwari and B. Chaturvedi, "High-input lowoutput impedance all-pass filters using one active element”, IET: Circuits Devices and Systems, vol. 6, pp. 103-110, 2012.

[21] S. Maheshwari and M. S. Ansari, "Catalog of realizations for DXCCII using commercially available ICs and applications”, Radioengineering, vol. 21, pp. 281-289, 2012.

[22] K. M. Al-Ruwaihi, “A floating voltage controlled linear resistor and its application to active RC filters", International Journal of Electronics, vol. 92, pp. 483498, 1997.

[23] M. Bhusan and R. W. Newcomb, “Grounding of capacitors in integrated circuits”, Electronics Letters, vol. 3, pp. 148-149, 1967.

[24] S. Minaei and E. Yuce, "Un ity/variable-gain voltagemode/current-mode first-order all-pass filters using single dual-X second-generation current conveyor", IETE Journal of Research, vol. 56, pp. 305-312, 2010.

[25] P.E. A llen and D.R. Holberg, "CMOS analog circuit design,” Oxford University Press, 2004, 2nd edn.

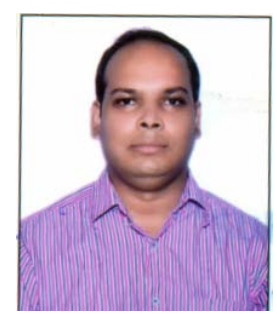

Jitendra Mohan obtained his B. Tech. degree from S. R. T. M. University, Nanded in 1997. He got his M.Tech degree from Aligarh Muslim University in 2005 and Ph.D. degree from Uttarakhand Technical University in 2011. He is currently working as an Assistant Professor in the Department of Electronics and Communication Engineering at Jaypee Institute of Information Technology, Noida (India). His main areas of interest are current-mode circuits and analog signal processing applications. He has guided 01 Master’s
Dissertation and 10 projects. He has more than 24 International Journal and conference papers.

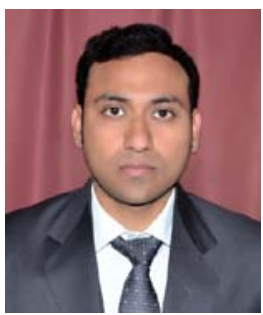

Bhartendu Chaturvedi received B. Tech. degree in Electronics \& Communication Engineering in 2005 and $M$. Tech. degree in Electronics Engineering, with specialization in Electronic Circuits and System Design in 2008. He is about to submit his $\mathrm{Ph}$. D. from Department of Electronics Engineering of Aligarh Muslim University, India. He is currently working as a Senior Lecturer in the Department of Electronics and Communication Engineering of Jaypee Institute of Information Technology, Noida, India. His research interests include Analog Signal Processing, Circuits \& Systems. He has published around 15 research papers in reputed international journals \& conferences and also authored 1 book chapter.

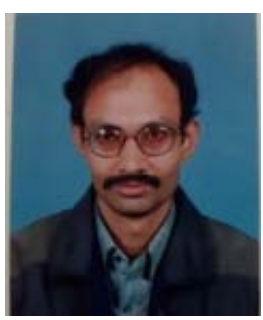

Sudhanshu Maheshwari served Harcourt Butler Technological Institute, Kanpur (India) for around four years as Lecturer. He jo ined the Department of Electronics Engineering, Aligarh Muslim University in year 2000 and is currently working as Associate Professor. He has been engaged in teaching and design of courses in the area of Analog Integrated Circuits and Current-mode Circuits. His research areas are analog signal processing circuits and current mode circuits. He has published around 95 research papers which includes 70 International Journal papers since year 2000. He is also the author of four book chapters. He has been the author as well as reviewer for several International journals like IET: Circuits Devices \& Systems, Int. J Electronics, Circuits Systems and Signal Processing, Int J Circuit Theory and Applications, Journal of Circuits Systems and Computers, Radio-engineering Journal, Active and Passive Electronic components, J Active and Passive Electronic Devices, Int. J Computer Applications, Microelectronics Journal etc. He is the member of the Editorial Board of International Journal: Active and Passive Electronic Components. 